\title{
Voting over taxes: the case of tax evasion
}

\author{
Christian Traxler
}

Received: 11 September 2007 / Accepted: 10 February 2009 / Published online: 4 March 2009

(c) The Author(s) 2009. This article is published with open access at Springerlink.com

\begin{abstract}
This paper studies majority voting on taxes when tax evasion is possible. We characterize the voting equilibrium where the agent with median taxed income is pivotal. Since the ranking of true incomes does not necessarily correspond to the ranking of taxed incomes, the decisive voter can differ from the median income receiver. In this case, we find unconventional patterns of redistribution, e.g., from the middle class to the poor and the rich.
\end{abstract}

Keywords Majority voting · Tax evasion · Redistribution

JEL Classification H26 · D72

\section{Introduction}

You've got to be careful about this rhetoric, we're only going to tax the rich. ... The rich in America happen to be the small business owners. ... Just remember, when you're talking about, oh, we're just going to run up the taxes on a certain number of people-first of all, real rich people figure out how to dodge taxes. And the small business owners end up paying a lot of the burden of this taxation.

George W. Bush, 9th Aug. 2004. ${ }^{1}$

One of the cornerstones of the political-economic literature is the analysis of voting over tax schedules. The seminal contributions by Romer (1975), Roberts (1977) and Meltzer and Richard (1981) study majority voting on tax rates, where the median income receiver determines the political outcome. The present paper extends this analysis by introducing

\footnotetext{
${ }^{1}$ See http://www.whitehouse.gov/news/releases/2004/08/20040809-3.html, accessed July 2008.

This article is based on sections $1-3$ in Traxler (2006).

C. Traxler $(\bowtie)$

Max Planck Institute for Research on Collective Goods, Kurt-Schumacher-Strasse 10, 53113 Bonn,

Germany

e-mail: traxler@coll.mpg.de
} 
tax evasion. While the empirical importance of evasion is well-documented, ${ }^{2}$ there is no comprehensive analysis of income tax evasion within the classical median voter framework. ${ }^{3}$ Our approach attempts to close this gap in the literature.

Allowing taxpayers to conceal a part of their income from taxation alters the standard results in several interesting ways. First of all, individuals' preferences over alternative tax rates are determined by their true pre-tax incomes rather than by their reported taxable incomes. Second, the ranking of agents according to pre-tax income does not necessarily correspond to the ranking of taxed incomes. This implies that voters' preferences for taxation are not necessarily monotonic in their true income. If, for instance, taxpayers from the top of the income distribution can more easily conceal income than individuals with intermediate income levels - as suggested in the quote from former US president George W. Bush - the taxed income of the 'real rich' might be lower than the taxed income of the middle class and the 'small business owners', respectively. If this is the case, high income groups ceteris paribus prefer higher taxes than voters from the middle class. An untypical coalition of poor and rich would emerge, with both groups voting for higher taxes. Consequently, the tax system would redistribute from the middle class to the poor and to the rich. ${ }^{4}$ The nonmonotonicity of preferences over taxes in true income furthermore implies that the pivotal taxpayer - the agent with the median taxed income-does not necessarily correspond to the voter with the median pre-tax income.

Our approach combines the literature on income tax evasion (see e.g., Andreoni et al. 1998) and the political-economic literature on voting over taxation (Persson and Tabellini 2000). Thereby, we deviate from the standard model of income tax evasion (Allingham and Sandmo 1972), where risk-averse taxpayers trade off the costs of detection against the tax savings when they get away with the evasion. Instead, we consider risk-neutral agents who face convex costs of concealing income. ${ }^{5}$ In this vein, the framework can captures both, illegal tax evasion as well as legal tax avoidance. Our approach is similar to models of firm evasion (e.g., Cremer and Gahvari 1993; Stöwhase and Traxler 2005) and to reducedform models of tax avoidance (e.g., Slemrod 2001). However, none of these contributions considers voting over taxes.

We study the case where incomes are exogenously given ${ }^{6}$ and the opportunities-and thus, the costs - of (legally) avoiding or (illegally) evading taxes vary with the income level, similar as in Slemrod (2001). These income-related costs can be interpreted as a representation of the fact that different income groups derive their earnings typically from different

\footnotetext{
${ }^{2}$ In the United States, the IRS estimated the 'tax gap'- the difference between actual and hypothetical tax revenues without evasion - to amount to a total of $\$ 345$ billion in the year 2001 (Slemrod 2007). Frey and Feld (2002) assess the income tax gap for Switzerland at more than $17 \%$.

${ }^{3}$ Compare Gërxhani (2004), who surveys the literature on the economics of the informal sector from a public choice perspective.

${ }^{4}$ Similar examples of 'ends against the middle'-conflicts are discussed e.g., in Epple and Romano (1996) and Gouveia (1997).

${ }^{5}$ As has been pointed out by Cowell (1990), one could formulate the Allingham-Sandmo model in terms of the explicit costs for risk taking. In this way, however, we would have to shift the focus of our analysis from our main interest-voting in the context of evasion-to individual risk-taking. Moreover, note that the expected utility approach of tax evasion seems to have low explanatory power (see e.g., Frey and Feld 2002; Andreoni et al. 1998).

${ }^{6}$ The empirical literature suggests that (illegal) evasion and (legal) avoidance responses to taxation are quite big - at least in comparison with rather small changes in labour supply (compare e.g., Feldstein 1995, as well as the discussion in Kopczuk 2001; Roine 2006). We therefore leave the analysis of endogenous labour supply within this framework for future research.
} 
sources—capital or labour income, from self-employment or employed labour-which determine, e.g., their ability to exploit tax loopholes or their chances of successfully dodging taxes. ${ }^{7}$ Within this framework we analyze tax evasion and majority voting over a proportional income tax, which is used to finance a public good.

There are only a few other contributions on majority voting in a similar context. ${ }^{8}$ Borck (2009) analyzes voting over redistribution with tax evasion. Evasion is modeled along the lines of Allingham and Sandmo (1972) and tax revenues are used to finance a lump-sum transfer. Roine (2006) studies a model of majority voting on taxes in the presence of legal tax avoidance. Agents make a discrete choice, either to invest a fixed amount and explore a given avoidance opportunity or to declare all their income. Roine (2003) generalizes the approach, considering the case of continuous tax avoidance and endogenous labour supply. Similar to our paper, these contributions show that tax evasion as well as avoidance typically drives a wedge between the ranking of pre-tax and taxed income. In turn, this will shifting the position of the decisive voter away from the median income receiver, which triggers similar patterns of redistribution as in our analysis. In the models of Borck (2009) and Roine $(2003,2006)$, however, voters' preferences regarding taxation satisfy neither singlepeakedness nor single-crossing. As the median voter theorem is in general not applicable and a voting equilibrium may not exist, the authors use numerical examples to discuss the properties of different equilibria.

The remainder of the paper is structured as follows. In Sect. 2 we set up the basic model and analyze the agents' evasion behavior. Section 3 studies the taxpayers' voting incentives. We characterize the voting equilibrium and discuss possible patterns of redistribution associated with different types of equilibria. A brief discussion of our main findings concludes the paper.

\section{Basic model}

An agent $i$ receives an exogenous pre-tax income $y_{i}, 0<y^{l} \leq y_{i} \leq y^{h}<\infty$, which is subject to a linear income tax at rate $\tau, 0<\tau<1$. The taxpayer chooses to conceal a share $e_{i} \in$ $[0,1]$ of his income. Hiding income from authorities entails (non tax-deductible) costs of $c\left(y_{i}, e_{i}\right)$, related to the individual's evasion efforts. ${ }^{9}$ These costs depend on the income level, as different income groups-which may derive their incomes from different sources (e.g., capital or labour, self-employed or employed labour)—face different opportunities to dodge taxes. Throughout our analysis we assume that $c(.,$.$) is continuously differentiable with$

\footnotetext{
${ }^{7}$ Slemrod (2007) reports that in the US 57\% of (nonfarm) proprietor income was not reported in 2001, whereas only one $1 \%$ of wages and salaries were underreported. Similar results are discussed in Engström and Holmlund (2006). Compare also Bloomquist (2003), Cox (1984), Fratanduono (1986).

${ }^{8}$ In a slightly different approach, Barbaro and Südekum (2009) study voting over tax exemptions. Similar as our analysis, they find that the decisive voter does not necessarily correspond to the median income receiver. Ahrend and Winograd (2006) analyze privatization in the presence of tax evasion and discuss under which conditions a coalition of poor and rich can emerge. Ahrend et al. (2007) provide a political economy analysis of inflation and taxation. The voting equilibria, which are comparable to those derived in the present paper, can also be supported by unconventional coalitions.

${ }^{9}$ Note that our set up, employing individual evasion costs, can be interpreted as a reduced form model of the case where the detection probability depends on the share of income concealed as well as on the income level. For other studies which use individual evasion cost functions see e.g., Kopczuk (2001) or Slemrod (2001).
} 
$c_{e}\left(y_{i}, e_{i}\right) \geq 0, c_{e}\left(y_{i}, 0\right)=0, c_{e}\left(y_{i}, 1\right)=\infty$ and $c_{e e}\left(y_{i}, e_{i}\right)>0 .{ }^{10}$ With a fixed probability $p$ an evader gets detected and has to pay full taxes plus a penalty proportional to the taxes evaded (Yitzhaki 1974). ${ }^{11}$ If the taxpayer gets away with the evasion, only the declared income is taxed.

The expected after-tax income is then given by

$$
E Y\left(y_{i}, e_{i}\right)=(1-p)\left(y_{i}(1-\tau)+\tau e_{i} y_{i}\right)+p\left(y_{i}(1-\tau)-\tau e_{i} y_{i}(s-1)\right)-c\left(y_{i}, e_{i}\right)
$$

which simplifies to

$$
E Y\left(y_{i}, e_{i}\right)=y_{i}\left(1-\tau+e_{i} \tau(1-p s)\right)-c\left(y_{i}, e_{i}\right),
$$

where $s>1$ denotes the penalty rate. Expected fines are assumed to satisfy $p s<1$, such that evading income yields a positive return. For the special case $p=0$ our approach can be interpreted as a model of legal tax avoidance, similar to Roine (2006). However, our framework is more general, as we consider a continuous (illegal) evasion or (legal) avoidance decision. (To see this point, note that all our results also hold for the special case $p=0$.) Hence, our analysis covers all forms of tax-reducing activity.

The preferences of risk neutral agents are characterized by an additively separable utility function defined over expected income $E Y(.,$.$) and a public good g$,

$$
U\left(y_{i}, e_{i}, g\right)=E Y\left(y_{i}, e_{i}\right)+V(g),
$$

with $V($.$) being continuously increasing and strictly concave. Taxpayers choose e_{i}$ so as to maximize (2). The first-order condition to this problem,

$$
y_{i} \tau(1-p s)=c_{e}\left(y_{i}, e_{i}\right),
$$

characterizes $e_{i}^{*}$, the optimal share of income concealed, for a given set of policy variables and an income $y_{i}{ }^{12}$ Using the implicit function theorem on (3) one can easily derive

$$
\frac{\partial e_{i}^{*}}{\partial p}<0, \quad \frac{\partial e_{i}^{*}}{\partial s}<0, \quad \frac{\partial e_{i}^{*}}{\partial \tau}>0 .
$$

While stricter tax enforcement - an increase in the detection probability and/or the penalty rate-will reduce evasion, a rise in the tax rate will trigger more evasion. Note that this last result is at odds with the classical model of income tax evasion. For the case of riskaverse taxpayers and a penalty structure as considered above (i.e., proportional to taxes evaded), non-increasing absolute risk aversion is sufficient to show that evasion decreases with higher tax rates (Yitzhaki 1974). As we consider risk neutral agents who face convex costs of concealing income, we get the more intuitive result that evasion increases as taxes rise. ${ }^{13}$

\footnotetext{
${ }^{10}$ We use $c_{e}\left(y_{i}, e_{i}\right)$ and $c_{e e}\left(y_{i}, e_{i}\right)$ for $\frac{\partial c(., .)}{\partial e}$ and $\frac{\partial^{2} c(., .)}{\partial e^{2}}$, respectively. Equivalently, $c_{e y}\left(y_{i}, e_{i}\right)$ denotes $\frac{\partial c(., .)}{\partial e \partial y}$.

${ }^{11}$ Our results also hold for the case originally studied by Allingham and Sandmo (1972), where the penalty is proportional to the concealed income rather than taxes evaded.

${ }^{12} \mathrm{We}$ focus on interior solutions by assuming $c_{e}\left(y_{i}, 0\right)=0$ and $c_{e}\left(y_{i}, 1\right)=\infty$. The second-order condition is fulfilled since $c_{e e}\left(y_{i}, e_{i}\right)>0$.

${ }^{13}$ Following a similar modeling approach, the same result is derived in the literature on tax evasion of firms (see e.g., Cremer and Gahvari 1993; Stöwhase and Traxler 2005).
} 
From (3) we get

$$
\frac{\partial e_{i}^{*}}{\partial y_{i}}=\frac{\tau(1-p s)-c_{e y}\left(y_{i}, e_{i}^{*}\right)}{c_{e e}\left(y_{i}, e_{i}^{*}\right)} .
$$

Although the marginal benefits of evasion are (linearly) increasing in income, the sign of $\partial e / \partial y$ is ambiguous and depends on the cross derivative of the cost function-i.e., on how the marginal costs of concealing change with the income level. If the inequality

$$
c_{e y}\left(y_{i}, e_{i}^{*}\right) \geq \tau(1-p s)
$$

holds, the share of concealed income $e_{i}^{*}$ is non-increasing in income. In this case, the marginal costs of dodging taxes are strongly increasing in income, such that richer taxpayers would declare a larger share of their true income than poorer agents. ${ }^{14}$ However, if the marginal costs of concealing are declining (as assumed in Slemrod 2001) or not too strongly increasing in income, condition (5) would be violated. In this case, the share of income concealed would increase as income rises: Richer taxpayers would conceal a larger share of their income as compared to poorer agents. In the following we will consider both possible cases.

Finally, we specify the public sector of the economy. We consider a continuum of individuals with incomes distributed according to a continuously differentiable cumulative distribution function $F(y)$ with $y \in\left[y^{l}, y^{h}\right]$. In the following $\bar{y}$ denotes the mean and $y^{m}$ the median of the income distribution. Revenues from taxes and fines are used to finance the public good. With a marginal rate of transformation of unity we get

$$
g=\tau \int_{y^{l}}^{y^{h}} y\left(1-e^{*}(y)(1-p s)\right) d F(y),
$$

where $e^{*}(y)$ denotes the solution to (3) as a function of income. Let us define

$$
x\left(y_{i}\right) \equiv y_{i}\left(1-e^{*}\left(y_{i}\right)(1-p s)\right),
$$

the - in expectation terms ${ }^{15}$ — taxed income of a taxpayer with true income $y_{i}$. Substituting for $x\left(y_{i}\right)$ we can express (6) as

$$
g(\tau)=\tau \int_{y^{l}}^{y^{h}} x(y) d F(y) \equiv \tau \bar{x},
$$

where $\bar{x}$ denotes the mean taxed income.

\section{Voting with tax evasion}

Let us now turn to voting over the tax rate within this framework. The following timing of events is considered: First, majority voting determines the tax rate. Second, taxpayers

\footnotetext{
${ }^{14}$ For the special case where (5) holds with equality-which would be the case if e.g., $c\left(y_{i}, e_{i}\right)$ were linear in $y_{i}$-the share of income concealed $e_{i}^{*}$ would be the same for all income levels.

${ }^{15}$ Note that $x\left(y_{i}\right)$ consists of the declare income, $y_{i}\left(1-e_{i}^{*}\right)$, as well as of the 'base' for the expected fine, ps $y_{i} e_{i}^{*}$.
} 
choose their optimal level of evasion and finally the revenues collected from taxation and auditing determine the level of the public good as in (6)-(8) above. Throughout this analysis the detection probability as well as the penalty rate are taken as exogenously fixed. ${ }^{16}$

\subsection{Voting equilibrium}

The most preferred tax rate of an agent with income $y_{i}$ is given by the solution to

$$
\max _{\tau} E Y\left(y_{i}, e_{i}^{*}\right)+V(g(\tau))
$$

with $e_{i}^{*}$ and $g(\tau)$ from (3) and (8), respectively. Making use of (3), we get the first-order condition

$$
V^{\prime} \frac{\partial g}{\partial \tau}=x\left(y_{i}\right)
$$

where $\partial g / \partial \tau$ is derived in the Appendix. There we also show that the second-order condition to this problem holds for all $y_{i} \in\left[y^{l}, y^{h}\right]$ as long as $V^{\prime} / y^{h}$ is sufficiently large. Given that this holds, (9) determines the most preferred tax rate of an agent where the marginal benefits of consuming $g$ equal her marginal costs from taxation. While the former are equal for all taxpayers, the latter depend on $x\left(y_{i}\right)$, the taxed income of an individual with true income $y_{i}$. From (9), it follows immediately that the preferred tax rate is decreasing in $x$ : The higher the taxed income, the more a taxpayer contributes to the public good and the lower is the desired tax rate. Ranking taxpayers according to their taxed income then yields the (reversed) ranking of voters' preferences for taxation. As we discuss in Appendix A.1, the median voter theorem is always applicable: Even if single-peakedness would be violated, the single-crossing condition is unambiguously satisfied (Gans and Smart 1996). The decisive voter is therefore characterized by the median level of $x\left(y_{i}\right)$. This result is summarized in

Proposition 1 Let the cumulative distribution of $x=x(y)$ be given by $H(x)$. The political equilibrium is characterized by

$$
V^{\prime} \frac{\partial g}{\partial \tau}=\hat{x}
$$

with $H(\hat{x})=\frac{1}{2}$.

Proof See Appendix.

The majority voting outcome characterized in Proposition 1 is analogous to the classical result (Romer 1975; Roberts 1977; Meltzer and Richard 1981). In the absence of tax evasion, preferences for taxation can be ranked according to the true incomes of taxpayers and the median income voter is pivotal. In our framework, however, agents are heterogenous in terms of the true income as well as in the levels of evasion efforts-which boils down to a distribution of taxed incomes. The political equilibrium is then determined by the taxpayer with median taxed income $\hat{x}$.

\footnotetext{
${ }^{16}$ As $p$ is kept constant, we normalize the public costs of providing a certain auditing level to zero. Note further, that our analysis neglects the case where the government can not credibly commit to an auditing policy. 
Table 1 Relation between $c_{e y}$ and $\partial x / \partial y$

\begin{tabular}{llll}
\hline Case & Condition on $c_{e y}$ & Properties & \\
\hline 1. & $\forall y \in\left[y^{l}, y^{h}\right]: c_{e y} \geq \tau(1-p s)$ & $\frac{\partial e^{*}}{\partial y} \leq 0$ & $\frac{\partial x}{\partial y}>0$ \\
2. & $\forall y \in\left[y^{l}, y^{h}\right]: \tau(1-p s)-\psi(y) \leq c_{e y}<\tau(1-p s)$ & $\frac{\partial e^{*}}{\partial y}>0$ & $\forall y \in\left[y^{l}, y^{h}\right]: \frac{\partial x}{\partial y} \geq 0$ \\
3. & $\exists y \in\left[y^{l}, y^{h}\right]: c_{e y}<\tau(1-p s)-\psi(y)$ & $\frac{\partial e^{*}}{\partial y}>0$ & $\exists y \in\left[y^{l}, y^{h}\right]: \frac{\partial x}{\partial y}<0$ \\
\hline
\end{tabular}

\subsection{Position of the median voter}

We now have to ask whether the decisive voter still correspond to the taxpayer with median true income. In order to address this question, we have to check if $x(y)$ is monotonic in $y$. From (7) we can easily derive

$$
\frac{\partial x\left(y_{i}\right)}{\partial y_{i}}=\left(1-e_{i}^{*}(1-p s)\right)-y_{i} \frac{\partial e_{i}^{*}}{\partial y_{i}}(1-p s) .
$$

The first term on the right-hand side of (10) is positive and depicts the increase in taxed income associated with a rise in $y_{i}$. The second term captures the change in the evasion behavior due to an increase in true income. Since this second effect might be negative, the sign of $\partial x / \partial y$ is ambiguous and crucially depends on $\partial e^{*} / \partial y$ from (4), which itself is determined by the sign of $c_{e y} .{ }^{17}$ We can distinguish between three different cases:

1. If $\partial e^{*} / \partial y \leq 0$ holds (for all income levels), the share of income concealed $e_{i}^{*}$ decreases and taxable income $x\left(y_{i}\right)$ monotonically increases in incomes. In this case, preferences for taxation are monotonic in true income and the median voter corresponds to the taxpayer with the median income.

2. If $\partial e^{*} / \partial y$ is positive but the first term in (10) dominates the second for all income levels, we still get $\partial x / \partial y>0$. Preferences for taxation are monotonic in the true income and the decisive voter is the median income receiver.

3. With $\partial e^{*} / \partial y$ being positive, however, there might exist income levels where the second term in (10) dominates the first. In this case, agents would increase the share of income concealed such that the higher level of evasion outbalances the income increase. Consequently, taxed income is (locally) decreasing in true income. Voters' preferences for taxation are no longer monotonic in income. As a consequence, the median voter might differ from the median income receiver.

One can distinguish between these cases according to the value of $c_{e y}$, which determines the size and sign of $\partial e / \partial y$. In Table 1 we used (4) in (10) to derive thresholds for the three possible scenarios, where $\psi(y)$ is defined as

$$
\psi(y) \equiv \frac{1-e^{*}(y)(1-p s)}{y(1-p s)} c_{e e} .
$$

If the marginal costs of concealment are strongly increasing in income such that (5) holds, we are in case 1 . If (5) is violated, we are either in case 2 or case 3 . If $c_{e y}$ does not fall too short of the threshold $\tau(1-p s)$, the condition for case 2 might hold for all income levels. The smaller is $c_{e y}$, the more likely we arrive at case 3 . Note, however, that it is not at all

${ }^{17}$ Compare condition (5) and the discussion in Sect. 2. 
necessary for $c_{e y}$ to be negative to get the third case. ${ }^{18}$ Even if the marginal costs of evasion are increasing in income, i.e., $c_{e y}>0$, the ranking of taxed incomes can differ from the ranking of true incomes. These findings lead us to the following proposition:

Proposition 2 1. If $c_{e y} \geq \tau(1-p s)-\psi(y)$ holds for all income levels $y \in\left[y^{l}, y^{h}\right]$ we get $\frac{\partial x(y)}{\partial y} \geq 0$ for all agents. Voters' preferences for taxation are monotonic in income and the median income receiver is pivotal, $\hat{x}=x\left(y^{m}\right)$.

2. If there exits an income $y \in\left[y^{l}, y^{h}\right]$ such that $c_{e y}<\tau(1-p s)-\psi(y)$, we locally get $\frac{\partial x(y)}{\partial y}<0$. Voters' preferences for taxation are non-monotonic in $y$. The decisive voter will be different from the median income receiver, $\hat{x} \neq x\left(y^{m}\right)$,

2.a if $\exists y \in\left(y^{m}, y^{h}\right]$ with $x(y)<x\left(y^{m}\right)$ and $\nexists y \in\left[y^{l}, y^{m}\right)$ with $x(y)>x\left(y^{m}\right)$.

In this case we get $\hat{x}<x\left(y^{m}\right)$.

2.b if $\nexists y \in\left(y^{m}, y^{h}\right]$ with $x(y)<x\left(y^{m}\right)$ and $\exists y \in\left[y^{l}, y^{m}\right)$ with $x(y)>x\left(y^{m}\right)$. In this case we get $\hat{x}>x\left(y^{m}\right)$.

2.c if $\exists y \in\left(y^{m}, y^{h}\right]$ with $x(y)<x\left(y^{m}\right)$ and $\exists y \in\left[y^{l}, y^{m}\right)$ with $x(y)>x\left(y^{m}\right)$. In this case we either get $\hat{x}<x\left(y^{m}\right), \hat{x}>x\left(y^{m}\right)$ or $\hat{x}=x\left(y^{m}\right)$.

2.d Otherwise, if $\nexists y \in\left(y^{m}, y^{h}\right]$ with $x(y)<x\left(y^{m}\right)$ and $\nexists y \in\left[y^{l}, y^{m}\right)$ with $x(y)>x\left(y^{m}\right)$, the median income receiver is pivotal, $\hat{x}=x\left(y^{m}\right)$.

Proof See Appendix.

While the first part of Proposition 2 subsumes scenarios one and two from Table 1, the second part specifies evasion costs which correspond to scenario three. For this last case, the pattern of tax evasion is such that taxed income-and thereby the ranking of preferences-is non-monotonic in pre-tax income. The subcases 2.a-2.c identify conditions under which this non-monotonicity drives a wedge between the position of the median voter and the agent with the median income. This occurs, if e.g., some taxpayers with above median-income strongly conceal income such that their taxed income falls short of the median income receiver's taxed income. In this case 2.a, the decisive voter has a lower taxed income than the agent with median income. Hence, the tax rate (as well as the public good level) in the voting equilibrium will be too high from the perspective of the median income receiver.

The opposite holds true for case 2.b: If some taxpayers from the lower half of the income distribution have a higher taxed income than the agent with median income, the decisive voter has a higher taxed income and therefore prefers a lower level of taxation as compared to the taxpayer with the median income. In case 2.c, where at the same time some agents from the upper half of the income distribution have a lower and some voters from the lower half have a higher taxed income than the median income receiver, the tax policy in the political equilibrium will (typically) be different from the policy preferred by the median income agent. Without any further restrictions, however, one cannot determine the direction of this deviation. Finally, in the case characterized in part 2.d of the proposition, the nonmonotonicity of preferences does not alter the position of the median income receiver as the decisive voter. Hence, the political equilibrium will be equivalent to the one which emerges in the case specified in part one of Proposition 2.

\footnotetext{
${ }^{18}$ Let us further remark that $\psi(y)$ tends to decreases in $y$. The numerator of $\psi(y)$ decreases in $y$ as in this range of $c_{e y}$ we have $\partial e / \partial y>0$. In addition, the denominator increases with $y$. Given that these are the dominant effects, i.e., if $c_{e e y}$ is not too strongly positive, we get $\partial \psi / \partial y<0$. Hence, for a given level of $c_{e y}$, the third case is particularly likely to hold for high income levels.
} 
What can we say about the plausibility of the cases characterized in the second part of Proposition 2? From a theoretical point of view it is worth noting that models of risk averse taxpayers imply that the share of concealed income is increasing in income-at least for the case of decreasing absolute risk aversion (see e.g., Andreoni et al. 1998, p. 838). A positive link between income also appears plausible if one considers an economy where the share of income, which is neither withheld nor directly reported to tax authorities, is increasing in pre-tax income. There is evidence suggesting that this is indeed the case-at least for the upper part of the income distribution: Bloomquist (2003) finds that middleincome taxpayers have the highest share-above $90 \%$ - of directly reported income. For top-income receives the rate drops to about $50 \%$. Given that income from e.g., capital and self-employed labour is easier to conceal, even decreasing marginal costs of evasion appear plausible. Hence, a non-monotonicity of taxed income as specified in the second part of Proposition 2 appears relevant, in particular, as evasion opportunities are crucial for actual underreporting behavior.

This claim is supported by evidence from the US. According to the IRS the underreporting rate in 2001 was $53.9 \%, 8.5 \%$, and $4.5 \%$ for income types subject to 'little or no', 'some', and 'substantial' information reporting, respectively (Slemrod 2007, p. 30). It is therefore not surprising that only $1 \%$ of wage and salaries but $57 \%$ of (nonfarm) proprietor income was not reported. Similar results are discussed in Engström and Holmlund (2006), who find that Swedish households with at least one self-employed member underreport around $35 \%$ of their incomes from self-employment. ${ }^{19}$ Anecdotal evidence which is in line with these findings is provided by Bergström and Gidehag (2003). They note that "more than half of the hairdressing employers in Sweden have a taxed income that is less than half of what a full-time employed hairdresser earns per annum ... ." Consistently with the evidence from above, the authors argue that the key explanation for this observation is the better evasion opportunities among employers as compared to employees. More general evidence is provided in studies of the elasticity of taxable incomes. Goolsbee (2000), Gruber and Saez (2002) as well as Slemrod (1994) suggest that the rich have better access to avoidance and evasion strategies than the middle class (compare also Roth et al. 1989, p. 137).

Some earlier studies point out a different aspect. Using random audit data of US taxpayers, Cox (1984) and Fratanduono (1986) find a U-shaped relationship between income and evasion with the smallest amount of evasion among taxpayers with median income levels. Hence, there might be a significant level of tax evasion among low income receivers-in particular related with the non-reporting of income from 'moonlighting' (compare Lemieux et al. 1994). A slightly different picture is provided in a recent study by Tedds (2008). Estimating evasion based on household expenditures, she finds underreporting to be larger for self-employed households at the lower end of the (self-employment) income distribution. Similar results are discussed in Fiorio and D'Amuri (2005).

Linking these last two pieces of evidence with our model, we shall stress that a nonmonotonicity of preferences can in principle emerge not only at the top but at any point of the income distribution (see Proposition 2, cases 2.b and 2.c, as well as Fig. 2). All what is necessary is that neighboring income groups face quite different opportunities (costs) of concealing income. In the light of the empirical evidence discussed above-with underreporting rates of more than $50 \%$ - such a non-monotonicity seems to be a possible scenario.

\footnotetext{
${ }^{19}$ This pattern is further corroborated by Mogensen (2004). They find, however, that evasion is nevertheless proportionally (and not over-proportionally) increasing in income.
} 


\subsection{Tax evasion and implicit redistribution}

A non-monotonicity of preferences in income has strong implications for the pattern of redistribution within our framework. To illustrate this point, let us discuss some examples. Figures 1-3 show the true income $y$ (horizontal axis) plotted against the taxed income $x(y)$ (vertical axis) for three evasion cost functions resulting in different shapes of $x(y)$. Without tax evasion, taxed income would equal true income. A vertical deviation from the 45 -degree line then captures the amount of income concealed from taxation (in expectation terms) at a give income level $y$.

The first figure describes an economy with widespread evasion among top-income receivers-the case suggested by George W. Bush in the paper's epigraph: 'Real rich people figure out how to dodge taxes', they conceal a huge part of their income. If 'only the little people pay taxes', as convicted tax evader Leona Helmsley put it, the voting equilibrium is supported by an unusual coalition of rich and poor, taxpayers with $y \in\left[y^{l}, \hat{y}_{0}\right]$ and $y \in\left[\hat{y}_{1}, y^{h}\right]$. In equilibrium 'the small business owners end up paying a lot of the burden of this taxation' - there is redistribution from the middle class, agents with $y \in\left[\hat{y}_{0}, \hat{y}_{1}\right]$ who have a taxed income above $\hat{x}$, to the poor and the rich, who both have a taxed income $x(y)<\hat{x}$.

A similar example, which also corresponds to scenario 2.a specified in Proposition 2, is given in Fig. 2. Here, the coalition supporting the equilibrium tax rate is formed by the poor with $y \in\left[y^{l}, \hat{y}_{0}\right]$ and the 'upper-middle class' with $y \in\left[\hat{y}_{1}, \hat{y}_{2}\right]$. These two groups benefit from redistribution to the disadvantage of the rich taxpayers, with $y \in\left[\hat{y}_{2}, y^{h}\right]$, as well as the 'lower-middle class' with $y \in\left[\hat{y}_{0}, \hat{y}_{1}\right]$. While this example shows the typical redistribution from the top to the bottom of the income distribution, we also observe an unusual direction of redistribution among the middle class-i.e., from the lower to the upper fraction of taxpayers with intermediate levels of income. In terms of the observation from Bergström and Gidehag (2003), there is redistribution 'from the hairdressers to their employers'.

The reason here is again that, locally, an income increase leads to an over-proportional increase in evasion such that the ranking of the taxed income among the middle class gets

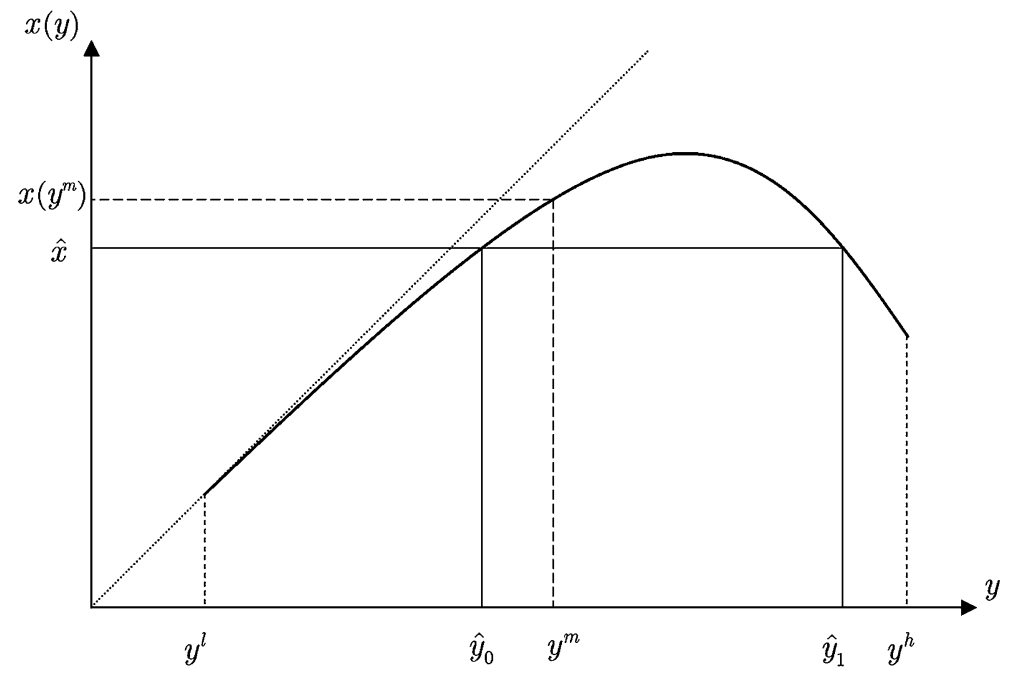

Fig. 1 Voting equilibrium and patterns of redistribution-example 1 


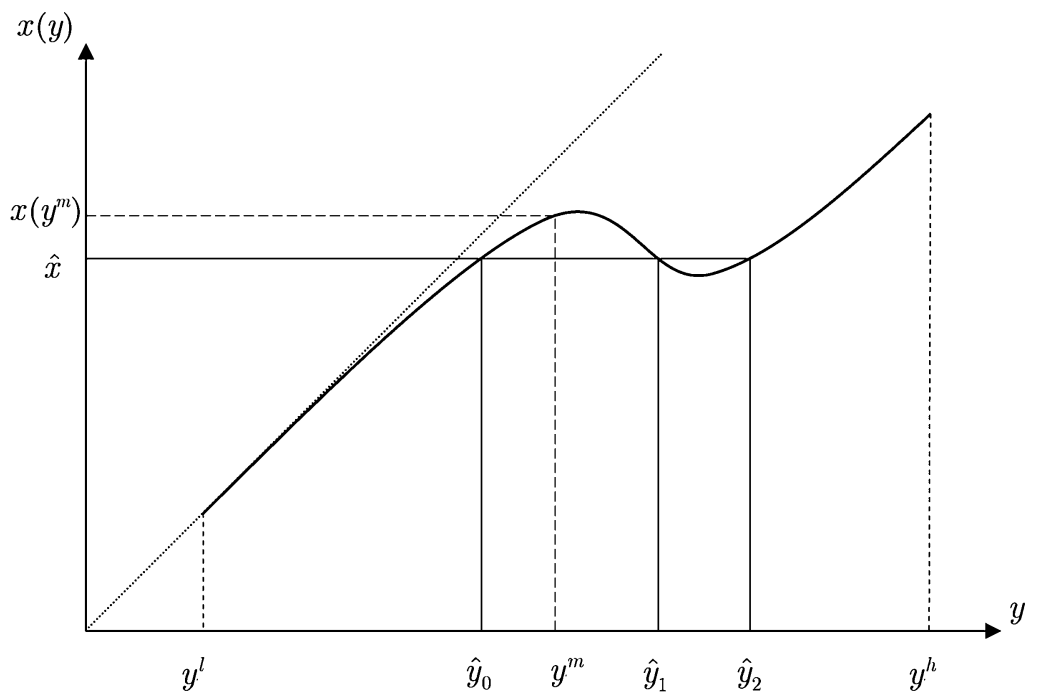

Fig. 2 Voting equilibrium and patterns of redistribution-example 2

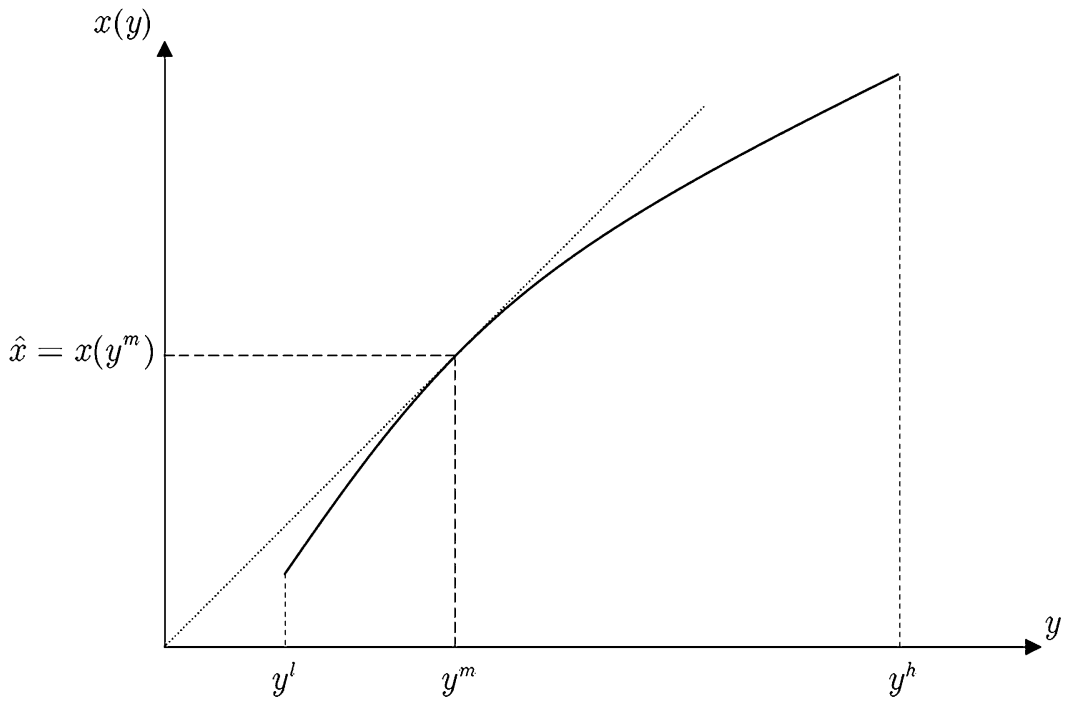

Fig. 3 Voting equilibrium and patterns of redistribution-example 3

reversed. Beyond the anecdote from Bergström and Gidehag (2003), this pattern is also motivated by the more systematic evidence in Tedds (2008) and Fiorio and D'Amuri (2005), which suggests that evasion is most pronounced for self-employed with rather low income levels. In turn, this could result in a redistributive conflict of low-income self-employed against workers with smaller incomes, where the latter nevertheless vote for lower taxes as they hardly conceal income.

Finally, the example in Fig. 3 captures an inverted U-shaped evasion pattern as it is found in Cox (1984) and Fratanduono (1986). In line with the evidence in Bloomquist (2003) and 
Slemrod (2007), we consider a scenario where there is basically no evasion in the range of the median income level as e.g., most of their incomes are withheld at source or directly reported to tax authorities. In contrast, taxpayers among the lower as well as among the upper part of the income distribution underreport incomes. Evasion does not reverse the true income distribution. Consequentially, the median voter is the agent with the median income level as characterized in part one of Proposition 2.

The emergence of unusual patterns of redistribution in the context of tax evasion or tax avoidance is not new in the literature. Both Borck (2009) and Roine $(2003,2006)$ find scenarios similar to the one described in Fig. 1. Borck (2009) considers a society consisting of three agents, who can either evade nothing at all or everything. A similar approach is provided by Roine (2006), who studies (legal) tax avoidance. His taxpayers can either invest a fixed amount to reduce their taxable income by a fixed share or they declare their full income. While the median voter theorem is typically not applicable in these frameworks, both authors discuss numerical examples of equilibria, where the tax system distributes from the middle class to the poor and the rich taxpayer. Similar cases are derived in Roine (2003), studying a continuous tax avoidance decision together with endogenous labour supply. In comparison to our approach, however, these contributions exclude many interesting patterns of redistribution. In particular, these models can capture only a non-monotonicity of taxed income at the top of the income distribution. Hence, cases like the one depicted in Fig. 2, where taxed income is reversed among the middle class, are neglected in their studies. ${ }^{20}$ The same holds for scenarios characterized by part 2.b and 2.c of Proposition 2. For the scenario depicted in Fig. 3, we find the usual conflict between rich and poor. The evasion pattern nevertheless has clear implications for redistribution - the underreporting of incomes among the lower end of the distribution reduce, whereas evasion among the rich aggravates the inequality in disposable income.

\section{Conclusion}

This paper introduced tax evasion into a simple model of majority voting on taxes. Allowing taxpayers to conceal income has strong implications for the political-economic analysis: First of all, individual preferences over tax rates are determined by their taxed rather than their true pre-tax income. Given that the opportunities to dodge taxes vary between different income groups, some taxpayers are more inclined to evade taxes than others. As a consequence, the ranking of agents according to true income does not necessarily correspond to the ranking of taxed incomes. Hence, voters' preferences over tax rates may be non-monotonic in their pre-tax income. If this is the case, the decisive voter can differ from the median income receiver. This also implies the existence of voting equilibria based e.g., upon a coalition of poor and rich, with both groups voting for higher taxes than the middle class. More generally, we observe redistribution from taxpayers with lower to individuals with (relatively) higher pre-tax incomes, if the latter conceal sufficiently more taxes than the former. Therefore, the distributional conflict emerges not only along income lines but also between those who comply with tax laws and those who cheat on taxes. Given the empirical relevance of tax evasion, tax compliance represents an important dimension of redistribution,

\footnotetext{
${ }^{20}$ In principle, our model could also accommodate equilibria which are supported by a coalition of the rich and the middle class voting for lower taxes than the poor (compare Ahrend et al. 2007). Given the evidence in Bloomquist (2003) and Slemrod (2007), however, this case appears rather implausible.
} 
which so far received only little attention in the political-economic literature (Borck 2009; Roine 2006).

Our framework may serve as a starting point for several fruitful extensions. It would be interesting to introduce an endogenous labour supply in the analysis. One could enrich the model with occupational choice, which would provide an endogenous source for heterogenous evasion costs between different income or occupational groups. If one considers a multi-regional economy, regional variation in tax enforcement would induce differences in compliance behavior (see Young et al. 2001), which could either mitigate or aggravate the interregional inequality in disposable income. Another promising avenue for future research is a welfare analysis, which takes into account equity considerations. One could then study how the tradeoff between welfare gains and costs from inequality works under different patterns of evasion and how this tradeoff interact with voting incentives related to heterogenous tax evasion efforts.

Acknowledgements I would like to thank Rainald Borck, Andreas Haufler, Rudolf Kerschbamer, two anonymous referees and the editor for helpful suggestions. The paper has also benefited from comments from participants at the APET Meeting 2006 (Hanoi) and at seminars at the Universities of Bonn, Innsbruck and Munich. Any remaining errors are mine. Financial support by the German Research Foundation (DFG Research Grant SPP 1142) is acknowledged.

Open Access This article is distributed under the terms of the Creative Commons Attribution Noncommercial License which permits any noncommercial use, distribution, and reproduction in any medium, provided the original author(s) and source are credited.

\section{Appendix}

\section{A.1 Second-order conditions}

Revenues. From (8) we can easily derive

$$
\frac{\partial g}{\partial \tau}=\bar{x}-\tau(1-p s) \int y \frac{\partial e^{*}(y)}{\partial \tau} d F(y)
$$

and

$$
\frac{\partial^{2} g}{\partial \tau^{2}}=-(1-p s) \int y\left(2 \frac{\partial e^{*}(y)}{\partial \tau}+\tau \frac{\partial^{2} e^{*}(y)}{\partial \tau^{2}}\right) d F(y) \leq 0
$$

where $\partial^{2} e^{*}(y) / \partial \tau^{2}$ can be either positive or negative, but is assumed to be sufficiently large such that $g$ is concave in $\tau$. (A sufficient condition for this case is $c_{e e e} \leq 0$ which implies $\partial^{2} e^{*}(y) / \partial \tau^{2} \geq 0$.) As both $V^{\prime}$ and $x($.) are strictly positive, it follows from (9) that $\partial g / \partial \tau>$ 0 holds for the voting equilibrium. Hence, the relevant tax rates are on the upward-sloping side of the Laffer-curve.

Single-peakedness and single-crossing. The second-order condition to (9) is given by

$$
V^{\prime \prime}\left(\frac{\partial g}{\partial \tau}\right)^{2}-(1-p s)\left[V^{\prime} \int y\left(2 \frac{\partial e^{*}(y)}{\partial \tau}+\tau \frac{\partial^{2} e^{*}(y)}{\partial \tau^{2}}\right) d F(y)-y_{i} \frac{\partial e_{i}^{*}}{\partial \tau}\right] \leq 0,
$$

where we have substituted for (A.2). As the first term in (A.3) is strictly negative, it is sufficient for the inequality to hold, if the expression in the squared brackets is positive. As long as $V^{\prime}$ is high enough and as long as $y^{h}$ is not too high, this will be the case for all 
$y_{i} \in\left[y^{l}, y^{h}\right]$. Hence, single-peakedness 'requires' (in terms of sufficient conditions) two things: First, the marginal utility from the public good must be sufficiently large. This appears plausible if revenues and thereby spendings on the public good are constrained by widespread tax evasion. Second, (A.3) implies an implicit upper bound on the top-income, $y^{h+}$. Single peakedness will hold for all income levels, as long as $y^{h} \leq y^{h+}$.

For the case where (A.3) is violated for some income levels and single-peakedness does not hold for all agents, the median voter theorem can nevertheless be applied: The singlecrossing condition holds (Gans and Smart 1996), since voters' preferences over the $(\tau, g)$ space are monotonic in $x$. To see this, we derive from (2) the marginal rate of substitution

$$
\left.\frac{d g}{d \tau}\right|_{U=\bar{U}}=-\frac{\partial U / \partial \tau}{\partial U / \partial g}=\frac{x}{V^{\prime}}
$$

where we made use of (3).

\section{A.2 Proofs}

Proof of Proposition 1 Let us denote the tax rate preferred by the agent with a taxed income $\hat{x}$ as $\hat{\tau}$. Consider a vote between $\hat{\tau}$ and a tax rate $\tau^{\prime}<\hat{\tau}$. The higher tax rate will be clearly preferred by all agents with $x \leq \hat{x}$. Hence, the fraction of the population that prefers $\tau^{\prime}$ over $\hat{\tau}$ is less than $H(\hat{x})=\frac{1}{2}$. From this follows that no tax rate lower than $\hat{\tau}$ can defeat $\hat{\tau}$ by an absolute majority. From the same argument follows that no tax rater higher than $\hat{\tau}$ can win a majority vote against $\hat{\tau}$. Hence, the taxpayer with $\hat{x}$ is pivotal.

Proof of Proposition 2 1. Substituting (4) in (10) and using $c_{e y} \geq \tau(1-p s)-\psi(y) \forall y \in$ $\left[y^{l}, y^{h}\right]$, it follows that $\frac{\partial x(y)}{\partial y} \geq 0$ for all income levels. Hence, the ranking of taxpayers according to their true income $y$ corresponds to the ranking according to the taxed income $x$. From this and Proposition 1 immediately follows that the median income receiver is also pivotal.

2. Following the steps from above, the existence of a true income $y^{\prime} \in\left[y^{l}, y^{h}\right]$ for which $c_{e y}<\tau(1-p s)-\psi\left(y^{\prime}\right)$ implies that $\frac{\partial x\left(y^{\prime}\right)}{\partial y}<0$ holds for $y^{\prime}$. Therefore, the ranking of taxpayers according to their true income $y$ does no longer correspond to the ranking according to the taxed income $x$.

2.a Consider the case where $\exists y \in\left(y^{m}, y^{h}\right]$ with $x(y)<x\left(y^{m}\right)$ and $\nexists y \in\left[y^{l}, y^{m}\right)$ with $x(y)>x\left(y^{m}\right)$. The median income receiver can not be pivotal as there is a majority-formed by all agents with $y \in\left[y^{l}, y^{m}\right]$ as well as those agents with $y \in\left(y^{m}, y^{h}\right]: x(y) \leq x\left(y^{m}\right)$ with a taxed income lower than (or equal to) the median income receiver's taxed income. Formally, $H\left(x\left(y^{m}\right)\right)>\frac{1}{2}$. From this follows that the decisive voter must have a taxed income $\hat{x}<x\left(y^{m}\right)$.

2.b Consider now the case where $\nexists y \in\left(y^{m}, y^{h}\right]$ with $x(y)<x\left(y^{m}\right)$ and $\exists y \in\left[y^{l}, y^{m}\right)$ with $x(y)>x\left(y^{m}\right)$. Again, the median income receiver can not be pivotal. All agents with $y \in\left[y^{m}, y^{h}\right]$ as well as those agents with $y \in\left[y^{l}, y^{m}\right)$ who have $x(y) \geq x\left(y^{m}\right)$ form a majority, who have a higher (or equal) taxed income than the median income receiver. We get $H\left(x\left(y^{m}\right)\right)<\frac{1}{2}$ and the political equilibrium must be characterized by a taxpayer with $\hat{x}>x\left(y^{m}\right)$.

2.c If $\exists y \in\left(y^{m}, y^{h}\right]$ with $x(y)<x\left(y^{m}\right)$ and $\exists y \in\left[y^{l}, y^{m}\right)$ with $x(y)>x\left(y^{m}\right)$ it is ambiguous whether $H\left(x\left(y^{m}\right)\right)$ is bigger or small than $\frac{1}{2}$. Consequently we can get either the case from 2.a or 2.b above. For the special case where $H\left(x\left(y^{m}\right)\right)=\frac{1}{2}$ we can also get $\hat{y}=y^{m}$. 
2.d If $\nexists y \in\left(y^{m}, y^{h}\right]$ with $x(y) \leq x\left(y^{m}\right)$ and $\nexists y \in\left[y^{l}, y^{m}\right)$ with $x(y) \geq x\left(y^{m}\right)$, the nonmonotonicity of $x(y)$ does not alter the position of the median income receiver as the agent with the median taxed income. We get $H\left(x\left(y^{m}\right)\right)=\frac{1}{2}$ and therefore $\hat{y}=y^{m}$.

\section{References}

Ahrend, R., \& Winograd, C. (2006). The political economy of mass privatisation and imperfect taxation: winners and loosers. Public Choice, 126(1), 201-224.

Ahrend, R., Verdier, T., \& Winograd, C. (2007). The political economy of inflation, demonetisation, and redistribution. Why and when monetary disorder ends? Mimeo, DELTA-Ecole Normale Superieure.

Allingham, M., \& Sandmo, A. (1972). Income tax evasion: a theoretical analysis. Journal of Public Economics, 1, 323-338.

Andreoni, J., Erard, B., \& Feinstein, J. (1998). Tax compliance. Journal of Economic Literature, 36, 818-860.

Barbaro, S., \& Südekum, J. (2009). Voting on income-tax exemptions. Public Choice, 138(1), 239-253.

Bergström, F., \& Gidehag, R. (2003). Sweden's black economy. Axess, 8-2003.

Bloomquist, K. M. (2003). Tax evasion, income inequality and opportunity costs of compliance. Proceedings of the National Tax Association, 96th Annual Conference, Chicago.

Borck, R. (2009). Voting on redistribution with tax evasion. Social Choice and Welfare, 32, 439-452.

Cowell, F. A. (1990). Tax sheltering and the cost of evasion. Oxford Economic Papers, 42(1), 231-243.

Cox, D. (1984). Raising revenue in the underground economy. National Tax Journal, 37(3), 283-288.

Cremer, H., \& Gahvari, F. (1993). Tax evasion and optimal commodity taxation. Journal of Public Economics $50,261-275$.

Engström, P., \& Holmlund, B. (2006). Tax evasion and self-employment in a high-tax country: evidence from Sweden. CESifo Working Paper No. 1736.

Epple, D., \& Romano, R. E. (1996). Ends against the middle: determining public service provision when there are private alternatives. Journal of Public Economics, 62, 297-325.

Feldstein, M. (1995). The effect of marginal tax rates on taxable income: a panel study of the 1986 tax reform act. Journal of Political Economy, 103(3), 551-572.

Fiorio, C., \& D'Amuri, F. (2005). Workers' tax evasion in Italy. Bocconi University, Giornale degli Economisti, 64(2-3), 247-270.

Fratanduono, R. J. (1986). Trends in voluntary compliance of taxpayers filing individual tax returns. In IRS Research Division (Ed.), Trend analyses and related statistics: 1986 (IRS Document 6011), Washington.

Frey, B. S., \& Feld, L. (2002). Deterrence and morale in taxation: an empirical analysis. CESifo Working Paper No. 760.

Gans, J. S., \& Smart, M. (1996). Majority voting with single-crossing preferences. Journal of Public Economics, 59(2), 219-237.

Gërxhani, K. (2004). The informal sector in developed and less developed countries: a literature survey. Public Choice, 120(3-4), 267-300.

Goolsbee, A. (2000). What happens when you tax the rich? Evidence from executive compensation. Journal of Political Economy, 108(2), 352-378.

Gouveia, M. (1997). Majority rule and the public provision of a private good. Public Choice, 93(3-4), 221244.

Gruber, J., \& Saez, E. (2002). The elasticity of taxable income: evidence and implications. Journal of Public Economics, 84(1), 1-32.

Kopczuk, W. (2001). Redistribution when avoidance behavior is heterogeneous. Journal of Public Economics, $81(1), 51-71$.

Lemieux, T., Fortin, B., \& Frechette, P. (1994). The effect of taxes on labor supply in the underground economy. American Economic Review, 84(1), 231-254.

Meltzer, A. H., \& Richard, S. F. (1981). A rational theory of the size of government. Journal of Political Economy, 89, 914-927.

Mogensen, G. V. (2004). Skattesnyderiet og indkomstfordelingen. In Skat (Ed.), Skat-April 2004, Skatteministeriet, Kobenhavn. Available online at (last accessed 01 Feb. 2009) www.skm.dk/publikationer/skat/ skatau-april2004/skattesnyderietogindkomstfordelingen/.

Persson, T., \& Tabellini, G. (2000). Political economics: explaining economic policy. Cambridge: MIT.

Roberts, K. (1977). Voting over income tax schedules. Journal of Public Economics, 8, 329-340.

Roine, J. (2003). Voting over tax schedules in the presence of tax avoidance. SSE/EFI Working Paper 529, Stockholm University. 
Roine, J. (2006). The political economy of not paying taxes. Public Choice, 126(1-2), 107-134.

Romer, T. (1975). Individual welfare, majority voting and the properties of a linear income tax. Journal of Public Economics, 4, 163-185.

Roth, J. A., Scholz, J. T., \& Witte, A. D. (1989). Taxpayer compliance, Vol. 1: An agenda for research. Philadelphia: University of Pennsylvania Press.

Slemrod, J. (1994). On the high income laffer curve. In J. Slemrod (Ed.), Tax progressivity and income inequality. Cambridge: Cambridge University Press.

Slemrod, J. (2001). A general model of the behavioral response to taxation. International Tax and Public Finance, 8(2), 119-128.

Slemrod, J. (2007). Cheating ourselves: the economics of tax evasion. Journal of Economic Perspectives, $21(1), 25-48$.

Stöwhase, S., \& Traxler, C. (2005). Tax evasion and auditing in a federal economy. International Tax and Public Finance, 12(4), 515-531.

Tedds, L. (2008). Estimating the income reporting function for the self-employed. Mimeo, University of Victoria.

Traxler, C. (2006). Voting over taxes: the case of tax evasion. Discussion Papers in Economics 1188, University of Munich, Department of Economics.

Yitzhaki, S. (1974). A note on income tax evasion: a theoretical analysis. Journal of Public Economics, 3 , 201-202.

Young, M., Reksulak, M., \& Shughart, W. F. (2001). The political economy of the IRS. Economics and Politics, 13(2), 201-220. 